Geopolítica(s) Revista de estudios sobre espacio y poder ISSN: 2172-3958

https://dx.doi.org/10.5209/geop.69250

\title{
¿Qué mundo geopolítico después de 2020?
}

\author{
Barbara Loyer ${ }^{1}$ y Béatrice Giblin ${ }^{2}$
}

Recibido: 5 de mayo de 2020 / Aceptado: 10 de mayo de 2020

Resumen. Con la crisis del nuevo coronavirus los Estados Unidos parecen desvanecerse como potencia frente a las ambiciones chinas, mientras la debilidad europea es patente. Lo que pueda ocurrir entre el régimen autoritario de China y los Estados democráticos occidentales europeos o Estados Unidos depende mucho de consideraciones geopolíticas internas. Los casos de Francia y España, dos sociedades seriamente tocadas por esta crisis sanitaria, ilustran en el artículo estas incertidumbres internas que tienen sus consecuencias a nivel mundial.

Palabras clave: pandemia de COVID-19; potencias geopolíticas; Estados Unidos; Unión Europea; China; Francia; España.

\section{[en] What Geopolitical World after 2020?}

\begin{abstract}
With the new coronavirus crisis, United States seems to fade as a power in the face of Chinese ambitions, while the European weakness is evident. What may happen between the authoritarian regime of China and the western European democratic states or the United States depends a lot on internal geopolitical considerations. In this article, the cases of France and Spain, two societies seriously affected by this health crisis, illustrate the consequences worldwide deriving from internal uncertainties.
\end{abstract}

Keywords: COVID-19 pandemic; geopolitical powers; United States; European Union; China; France; Spain.

\section{[pt] Que mundo geopolítico após 2020?}

Resumo. Com a crise do novo coronavírus, os Estados Unidos perdem força como potência diante das ambições chinesas, e a fraqueza europeia é evidente. O que pode acontecer entre o regime autoritário da China e os estados democráticos da Europa Ocidental ou os Estados Unidos depende muito de considerações geopolíticas internas. Os casos da França e da Espanha, duas sociedades seriamente afetadas por essa crise sanitária, ilustram no artigo estas incertezas internas que têm suas consequências em todo o mundo.

Palavras-chave: pandemia da COVID-19; poderes geopolíticos; Estados Unidos; União Européia; China; França; Espanha.

1 Catedrática del Instituto Francés de Geopolítica, Universidad de París 8, Francia.

E-mail: barbara.loyer@univ-paris8.fr

2 Catedrática emérita del Instituto Francés de Geopolítica y directora de la revista Hérodote. 
Sumario. Introducción. 1. ¿China alcanzará el estatuto de líder mundial? 2. Francia ante el coronavirus: explosión de las desigualdades territoriales. 3. En España, la crisis sanitaria exacerba las divisiones geopolíticas internas. 4. ¿Una Unión Europea inexistente? Conclusión: ¿qué escenarios geopolíticos a corto y medio plazo? Referencias.

Cómo citar: Loyer, B., y Giblin, B. (2020). ¿Qué mundo geopolítico después de 2020? Geopolítica(s). Revista de estudios sobre espacio y poder, 11(Especial), 115-126.

\section{Introducción}

E1 21 de enero de 2020, el anuncio del confinamiento de la ciudad de Wuhan (doce millones de habitantes) y de la provincia de Hubei provocó asombro y estupor por su carácter inédito. Nos hizo pensar también que sólo un régimen político autoritario como el de China podía tomar decisiones tan radicales y disponía de los medios técnicos y tecnológicos para controlar eficazmente su población. La epidemia parecía un buen pretexto para acentuar el control sobre los ciudadanos. El número de muertos, finalmente no tan elevado para un país de más de mil millones de habitantes, y las sanciones contra los médicos que alertaron precozmente sobre la enfermedad, acreditaron esta visión de las cosas. Además, los pocos fallecidos en Europa, así como el desconocimiento por la gran mayoría de la población de lo que es una progresión geométrica - que llamamos, en lenguaje corriente, progresión exponencial-, contribuyó a subestimar durante varias semanas el riesgo de contagio del virus, comparado con el de la gripe, y su peligrosidad.

Ello explica que haya costado tanto admitir que estábamos ante una pandemia y que sólo el confinamiento podía romper la cadena de transmisión del virus. Más de la mitad de la población mundial se ha recluido en casa. Esta situación inédita tendrá consecuencias colosales en todos los campos, pero es muy difícil preverlas porque falta conocimiento sobre el comportamiento del propio virus. Parece que afecta menos a África, pero las estadísticas son escasamente fiables. No se sabe si las temperaturas elevadas alteran su virulencia. No se sabe la duración y el grado de inmunidad que puede conceder el haber sido infectado. No se sabe si los niños contagian más o menos que los adultos, etc.

Se repite que, después de esta pandemia, nada será como antes. Que la dominación de los Estados Unidos se desvanecerá frente a las ambiciones chinas y la debilidad europea. Que los regímenes autoritarios como el chino tendrán más éxito en su estrategia de desprestigio del sistema democrático, supuestamente menos eficaz. Se predice que la mundialización cambiará de rostro por el repliegue de los Estados y naciones en sus territorios y que vienen otras catástrofes, pues el calentamiento global y la extinción de masa de la especies tendrían conexiones con la amenaza sanitaria.

En este artículo queremos proponer un punto de vista que asocia las dimensiones internas (nivel nacional) y externas (nivel internacional) del análisis geopolítico. Lo que pueda ocurrir depende mucho de consideraciones internas. A nivel nacional, analizamos los casos de Francia y España, dos sociedades seriamente tocadas por esta crisis sanitaria. 


\section{1. ¿China alcanzará el estatuto de líder mundial?}

Desde el principio de esta pandemia, Estados Unidos, presidido por Donald Trump, ha abandonado claramente su posición de líder mundial. Sus fronteras aéreas y terrestres están casi cerradas, ha suspendido toda inmigración durante al menos sesenta días y no otorga ayuda a nadie, ni siquiera a sus aliados. Es una oportunidad para el gobierno chino, que podría ocupar la plaza que deja voluntariamente vacante el gobierno americano. Las ayudas que manda China, con epidemiólogos y material sanitario, desde Italia hasta Senegal, apoyadas por una comunicación casi propagandística - después de haber pedido mayor discreción acerca de la ayuda mandada por la UE en enero-, tienen un claro objetivo geopolítico. Se trata de valorar la eficacia del régimen político chino en su lucha contra la epidemia y en su ejemplar solidaridad internacional, insistiendo sobre las divisiones y los egoísmos europeos (hacia Italia, por ejemplo) o sobre el supuesto abandono de África por los países occidentales.

El precoz control de la epidemia permite a China una recuperación de su economía antes que los demás países. Además, éstos dependen de los productos sanitarios producidos en China (mascarillas, reactivos para las pruebas virológicas, medicamentos) y están por ello obligados a pasar bajo las horcas caudinas del mercado chino: aumento importante de los precios para productos tan indispensables como las mascarillas o el curare para los servicios de reanimación.

Sin embargo, para asegurarse los beneficios geopolíticos a corto, medio y largo plazo, se requieren varias condiciones.

Si bien el mercado chino se está desarrollando, lo esencial de su producción está destinado a ser exportado. Si la demanda no vuelve a crecer rápidamente en los países importadores, el crecimiento chino, ya muy ralentizado con la pandemia, se mantendrá a un nivel bajo. Aunque el comercio chino aumenta en la zona asiática, incluida la India, en 2017 la Unión Europea y los Estados Unidos atraían aún la tercera parte de sus exportaciones, y de estas zonas venían poco más del $20 \%$ de sus importaciones. Por lo tanto, China depende de la recuperación económica a nivel mundial. Es muy importante, porque la paz social se funda en la mejora del nivel de vida de la población. Unos conflictos internos unidos al descontento social, respondidos sólo con la represión policial, dañarían fuertemente la imagen que Xi Jinping quiere dar de su país, la de la prueba del éxito del modelo comunista chino y de su superioridad sobre las democracias.

Es necesario tomar en cuenta otro factor: el descubrimiento de una vacuna contra el coronavirus es un reto fundamental porque el país que lo descubra, aunque lo ponga gratuitamente a disposición del mundo, se beneficiará de ello de forma simbólica. Si lo descubren los chinos, su imperialismo, sostenido por un potente nacionalismo, se fortalecerá. Aumentará su confianza en su modelo político y su convicción de que hay que difundirlo en todo el mundo, como ya lo están haciendo mediante las obras de las nuevas rutas de la seda, que significan su soft power. Si, por el contrario, lo descubren los Estados Unidos, ya no se podrá utilizar con éxito la representación de la decadencia de América del Norte. Los regímenes democráticos saldrán reforzados, sobre todo si la vacuna es el resultado de la cooperación entre investigadores de diferentes países. ¿Es factible tal cooperación con científicos chinos? Es lógico dudar de ello. Pensábamos que una estrecha colaboración entre franceses y chinos se desarrollaría gracias a la creación conjunta, en Wuhan, 
del laboratorio especializado en el estudio de los virus más peligrosos. Sin embargo, nunca se ha concretado, probablemente por culpa de las autoridades chinas.

También conocemos el papel que juega la confianza en el ámbito de los negocios. El comportamiento de las autoridades chinas, que tardaron en informar sobre la epidemia, y la poca fiabilidad de sus empresas en tiempo de crisis, han socavado esa confianza. Entregaron productos defectuosos, no respetaron encargos, algunos fueros vendidos de nuevo a compradores que pagaban más. Además, la política china de asistencia a los Estados africanos, y la propaganda asociada, no le asegurará forzosamente mucho reconocimiento. A propuesta del presidente francés, se ha anunciado una moratoria de un año sobre los intereses de la deudas de los Estados africanos. Quizá dichas deudas se anulen al final. Si los préstamos chinos no se reembolsasen, mermaría la influencia y el poder de China, porque la deuda es también para China una herramienta de dominación. En Sri Lanka, cuando el gobierno de la isla no pudo reembolsar su deuda, China se apoderó del puerto que había contribuido a construir.

No se puede saber todavía si la China de Xi Jinping será o no la gran ganadora de la pandemia. Dependerá de la manera en que este virus acabe controlado, con tratamiento o vacuna.

\section{Francia ante el coronavirus: explosión de las desigualdades territoriales}

En Francia, el primer muerto conocido por el coronavirus, el 15 de febrero de 2020, fue un turista chino de 80 años originario de la provincia de Hubei. Como padecía una neumonía, había sido aislado. Algunos médicos señalan que otra persona salió en diciembre curada del virus, sin que se hicieran entonces más indagaciones. A finales de enero, unos franceses que estaban en Wuhan cuando empezó el confinamiento fueron repatriados y aislados durante dos semanas. Muchos comentaristas dijeron entonces que el gobierno exageraba acerca de este virus, y los médicos aseguraban en la televisión que no era nada más que una pequeña gripe. Hasta finales de febrero, las declaraciones de los especialistas en infecciones dejaban creer que el virus no circulaba en Francia. El jefe del servicio de las enfermedades infecciosas del hospital Bichat en París, Yazdan Yazdanpanah, responsable de un grupo de investigadores sobre infecciones en el Instituto Nacional de Salud e Investigación Médica (INSERM), experto de la OMS, declaraba en una televisión pública, el 26 de febrero, que había que "seguir estrechando manos y abrazándose". Pero añadió asimismo que el " $90 \%$ de la personas padecen síntomas leves, pero hay un $10 \%$ de casos graves y un $2 \%$ de mortandad. Es entre 10 y 20 veces más agresivo que la gripe" (Franceinfo, 2020a). Igualmente, Robin Thompson, especialista de la modelización matemática de las epidemias en la Universidad de Oxford, afirmó a finales de febrero, en el Science Media Centre británico, que "todavía no ha habido transmisión interhumana continua en Europa, lo cual significa que el riesgo para las poblaciones continúa siendo débil" (AFP, 2020).

En Francia, la entonces ministra de Salud, Agnès Buzyn, había declarado a principios de febrero: "Tenemos que preparar nuestro sistema de salud para afrontar una posible difusión pandémica; es decir, una circulación del virus en el territorio nacional" (Méréo, 2020). En aquel momento, la estrategia de las autoridades sanitarias era el aislamiento de cada persona enferma confirmada y el rastreo de las 
personas con quienes había estado en contacto. Era una estrategia apropiada, pero no fue suficiente.

A la infravaloración de la alta contagiosidad del virus se añadió un suceso particular: el encuentro de la Iglesia Evangélica de la Puerta Cristiana, en la última semana de febrero. Se reunieron 2.500 personas durante cinco días en Mulhouse, lo cual explica la gravedad de la epidemia en la Región del Gran Este, y también en el conjunto del territorio nacional, incluidos Córcega y el Ultramar, adonde regresaron los fieles después del encuentro.

Recordar estas declaraciones científicas y políticas, así como el contexto específico de Mulhouse, es necesario para entender cómo una situación bien controlada en febrero se deterioró brutalmente a principios de marzo. Sin el encuentro religioso de Mulhouse, la situación de la Región del Gran Este no hubiese sido catastrófica. Sin embargo, no es lo mismo en París y sus afueras (departamentos de Altos del Sena, Seine-Saint-Denis, Valle del Marne, Valle del Oise) a causa de la proximidad del aeropuerto de Roissy Charles De Gaulle, uno de los diez mayores del mundo. Estos territorios son los más afectados por los efectos de la mundialización. Confluyen flujos de extranjeros: turistas (Francia es primer destino mundial) y negocios (muchos de China), extrema movilidad planetaria, europea, nacional, regional y local (más de 5 millones de viajeros diarios en la red de transportes públicos) y densidad de población muy elevada (más de 21.000 habitantes por $\mathrm{km}^{2}$ ). Es lógico que el contagio haya sido rápido.

Las cinco regiones francesas más afectadas (Región del Gran Este, Île de France, Borgoña-Franco Condado, Auvernia-Ródano-Alpes, Alta Francia) están situadas en el este de Francia. La relación con el encuentro evangelista es evidente para la Región de Gran Este y Borgoña-Franco Condado. En la región AuverniaRódano-Alpes la aglomeración de Lyon es la más afectada y luego la ciudad de Saint-Étienne. Los demás departamentos de la región apenas contabilizan víctimas (dos muertos en el departamento del Cantal el 22 de abril). La tasa elevada de contaminación en la región norteña de Alta Francia se pueda explicar por el caso de un departamento cercano a París, el Oise, donde surgió un brote inexplicado en un colegio en febrero, cuando nadie pensaba que este virus podía ser tan contagioso y peligroso. Aunque las estadísticas en todo el mundo son todavía escasamente fiables, el mapa de los enfermos ingresados en servicios de reanimación el 27 de abril del 2020 (Figura 1), elaborado sobre la base establecimientos de salud que han declarado casos confirmados de COVID-19, ilustra esta geografía.

Las consecuencias geopolíticas para Francia son de varios tipos. Una de las más preocupantes es la desconfianza extrema de los ciudadanos hacia los responsables políticos, estén en el poder o en la oposición, voten a la derecha o a la izquierda. Según el análisis de una encuesta Ipsos-Sopra Steria, el 39\% de los franceses tiene confianza en el Gobierno para gestionar la crisis; el 45\% expresa rabia (Goar, 2020); el $32 \%$ dice recelar, frente a sólo el $8 \%$ de británicos suspicaces. Y, sin embargo, la gestión de la epidemia en el Reino Unido dista de haber sido ejemplar. Defendieron primero la inmunidad colectiva - la llamada inmunidad de rebaño$\mathrm{y}$, frente al rápido aumento del número de muertos, tomaron el 24 de marzo la decisión de confinar a la población. Los ciudadanos alemanes confían también en sus instituciones y electos. La desconfianza radical de los ciudadanos franceses hacia los responsables políticos, y también hacia los sindicalistas o los periodistas, es un fenómeno que surge en los años noventa. La persistencia de una tasa elevada de 
desempleo, el empeoramiento de la desigualdades sociales y territoriales, la ausencia de cambio a pesar de la alternancia de partidos en el poder, comparado con las enormes expectativas de los franceses hacia el Estado central, son factores que dañan la confianza. Esto se traduce en las urnas con el crecimiento regular del voto favorable al Frente Nacional (extrema derecha). Ello provocó en 2002 la eliminación en la primera vuelta del candidato socialista a presidente, Lionel Jospin. Las elecciones presidenciales del 2017 confirmaron la creciente adhesión a la ideas del FN: Marine Le Pen ganó en la primera vuelta más de 7 millones de votos (frente a 4,8 millones para su padre en 2002) y logró casi 3 millones de papeletas suplementarias entre las dos vueltas (mucho más que su padre quince años antes: 720.000 votos suplementarios entre las dos vueltas).

Figura 1. Enfermos ingresados en servicios de reanimación en Francia por causa de la COVID-19 (27 de abril de 2020)

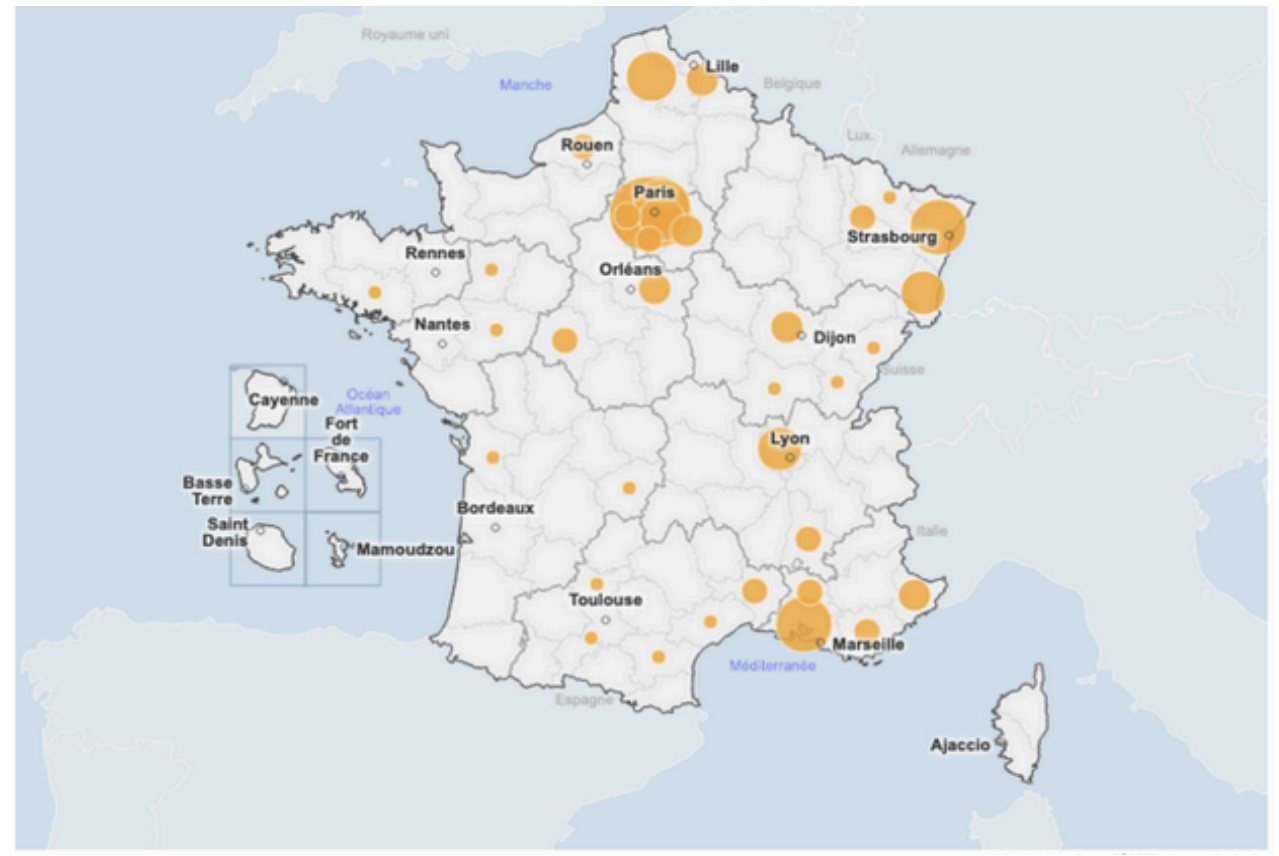

Fuente: Santé publique France-IGN.

Como el Frente Nacional, hoy transformado en Rassemblement National (Agrupación Nacional) —este cambio de nombre en 2018 estaba destinado a demostrar que el partido dirigido por la hija no es el del padre - , nunca ha ejercido el poder, sus electores pueden seguir creyendo que su futuro será mejor con él. La extrema derecha francesa, como el conjunto de los partidos populistas en el mundo, menciona a los trabajadores extranjeros como la primera causa de las dificultades económicas y sociales de las clases populares (obreros, empleados, autónomos, etc.). Su discurso tiene cada vez más impacto: reclama el cierre de las fronteras, la vuelta a la soberanía nacional abandonada en la Unión Europea, describe la mundialización como una amenaza para la identidad nacional (por los flujos migratorios que provoca). Después de haber dicho que era inútil cerrar las fronteras, mu- 
chos gobiernos, entre ellos el francés, se vieron obligados a cerrarlas. Tras haber defendido que la mundialización era fuente de crecimiento y bienestar, abundan los que hoy hablan de desarrollar nuevos sistemas industriales nacionales. Parte del electorado puede ver en ello una confirmación de la tesis del RN. Si la crisis se prolonga, los estragos económicos y sociales entre las poblaciones más frágiles serán dramáticos y pueden desembocar en violencias sociales en algunos barrios urbanos, en cólera entre amplias capas de la sociedad. Una parte tendrá la tentación de votar por la candidata del RN en 2022.

\section{En España, la crisis sanitaria exacerba las divisiones geopolíticas internas}

En España, como en Francia, la crisis sanitaria acentúa las fragilidades geopolíticas internas propias del país. La infravaloración de la gravedad del virus y la inexperiencia de lo que es una epidemia mortal han sido como mínimo equivalentes, tal vez superiores. Los primeros enfermos fueron noticia en varias Comunidades a finales de febrero (Madrid, Castilla-La Mancha, Cataluña). En Valencia, el primer fallecimiento se produce el 13 de febrero, pero se conoce que se debió a la COVID19 y se anuncia el 3 de marzo. Sin embargo las declaraciones son tranquilizadoras hasta el 9 de marzo. En Madrid, el 26 de febrero, cuando se contabilizan seis víctimas mortales en Italia, la Feria de Arte Contemporáneo (ARCO), abre sus puertas hasta el 1 de marzo, con once galerías italianas entre las 209 participantes, dos de ellas de Milán, otras dos de Turín y una de Bolonia, focos principales del virus en Italia. Hubo 93.000 visitantes, y las respuestas de los organizadores acerca de un eventual problema a causa del virus eran, en estas fechas, despreocupadas. Una querella contra la delegación del gobierno en Madrid afirma que fueron autorizadas decenas de manifestaciones el 7 y 8 de marzo, la mayoría para el Día de la Mujer, cuando Madrid contaba ya con más de 200 contagiados. Entre el 6 y el 9 de marzo, el número de personas infectadas es casi multiplicado por cuatro. La inconsciencia de la gravedad del virus ha sido compartida: el partido Vox organizó una asamblea multitudinaria (9.000 personas) ese mismo día en la Comunidad de Madrid.

No se habla mucho de los suburbios en España, tampoco de "barrios sensibles" como en Francia, sino de la debilidad del Estado central. Éste tuvo que poner en marcha una política nacional para la salud pública, a pesar de que haya sido completamente transferida a las Comunidades Autónomas entre 1981 (a Cataluña) y 2001. La descentralización ha consolidado la calidad del sistema sanitario español, pero en este contexto ha debilitado la respuesta coordinada a esta crisis tan violenta. También contribuye a complicar las estadísticas, que no son homogéneas y sí muy controvertidas: por ejemplo, según el Tribunal Superior de Justicia de la Comunidad de Castilla-La Mancha, en el mes de marzo, las licencias de enterramiento expedidas por los registros civiles de la región relacionadas con la COVID-19 fueron 1.921, lo cual casi triplica los datos oficiales de Sanidad (708 defunciones por este motivo). Cuando la Generalitat de Cataluña incluía en sus datos los fallecidos en residencias o domicilios, no lo registraban todavía las estadísticas oficiales del Ministerio de Sanidad. No se puede sacar un balance de la epidemia en España, y por eso también es prematuro comparar las cifras de los países. Los medias retienen sobre todo que España es de momento designada como el país que más muertos ha tenido por millón de habitantes. 
Las tensiones geopolíticas anteriores a la epidemia parecen agravarse con la tragedia. Los separatistas catalanes siguen con su estrategia de ruptura (la emergencia justifica ahora la voluntad de crear un ejército para tales contextos). La Asamblea Nacional Catalana, asociación separatista cuya función es azuzar a los políticos separatistas para lograr la independencia, está movilizada para que no sea en ningún caso aplazado el procés. No hubo atisbo de unión entre el Gobierno y la oposición. El Partido Popular, políticamente marginado durante el estado de alarma, construye su visibilidad en las grandes regiones que gobierna: Madrid (6,6 millones de habitantes), Andalucía $(8,4)$, recientemente conquistada al Partido Socialista, y Galicia $(2,7)$. Podemos sigue su agenda originaria que contempla la caída de la monarquía y la consiguiente proclamación de la república. El Partido Nacionalista Vasco reclama un papel, a poder ser exclusivo, para gestionar la situación en su Comunidad Autónoma y se preocupa sobre todo de las medidas económicas que tomará el Gobierno. Muchas políticas fiscales o sociales son competencia del Gobierno central.

El escenario de la profundización de un conflicto entre ciudadanos separatistas y constitucionalistas en Cataluña, germen de grave desestabilización, depende no obstante de las personalidades que estarán en el poder en el futuro próximo, a muy corto plazo, y por lo tanto de los calendarios electorales trastornados por el coronavirus. En enero del 2020, el presidente de la Generalitat, Quim Torra, había anunciado elecciones anticipadas, debido a las profundas divisiones internas en el campo separatista. Estas discrepancias no se han superado, al contrario, con la epidemia. El presidente ha renunciado finalmente a anticipar las elecciones, pero éstas dependen también de una sentencia del Tribunal Supremo aplazada por la pandemia. La crisis sanitaria desata asimismo rivalidades dentro de su propio partido, ya que el actual presidente, según algunas interpretaciones del campo independentista, debía dejar su puesto a Carles Puigdemont, huido a Bélgica. Pero después de haber dirigido Cataluña en tiempo de coronavirus, Quim Torra no parece tan convencido de que tenga que dejarle su sitio. El ministro de Sanidad español es un socialista catalán. Era secretario de organización del PSC. ¿Quién sabe cómo impactará este episodio sobre este partido? Las divisiones internas de los principales actores políticos catalanes sugieren que la nueva normalidad será muy similar a la vieja normalidad geopolítica en Cataluña y que la pandemia no amplía las vistas de los partidos políticos.

En Euskadi, el Partido Nacionalista Vasco se halla en situación de partido bisagra y la gestión prudente de esta ventaja le permite ensanchar regularmente las competencias y los recursos de gobierno. La epidemia no cambia esta dinámica.

A nivel nacional, no hubo unión durante la crisis y varios sondeos en abril muestran que los partidos que podrían salir perjudicados son los que aparecieron desde 2011. En Francia hablamos mucho del día después para preguntarnos si será igual o muy diferente. En España hablan de "nueva normalidad". El "día después" en España se parecerá sin duda bastante al "día precedente". Cada poder territorial defiende esencialmente prerrogativas. La depresión económica del 2008 dio la señal de salida al conflicto asumido por los separatistas catalanes. No sabemos los impactos que tendrá la crisis económica inminente. Tampoco se sabe hasta qué punto la Unión Europea quedará afectada por este seísmo. 


\section{4. ¿Una Unión Europea inexistente?}

La Unión Europea ha sido hasta ahora una suerte de horizonte colectivo de la sociedad española, mas allá de sus profundas divisiones. La UE representaba la democracia y la modernidad. Durante la crisis del 2008, el gobierno de Mariano Rajoy se felicitó de que su país no fuese tratado de la misma manera que Grecia, y las críticas de la izquierda acerca de la gestión de la consecuencias sociales del crack bursátil fueron dirigidas en contra del Gobierno, no de la UE. Los tribunales europeos de Justicia son un recurso frecuente de los ciudadanos para todo tipo de causa.

Para los franceses, la UE sigue teniendo también un valor político positivo. Marine Le Pen, cuyo partido es soberanista/nacionalista, tuvo que abandonar la idea de una salida del euro o de la UE a fin de consolidar sus buenos resultados. Difunde, sin embargo, a finales de febrero la idea de que la UE es inútil: "la Unión Europea (...) no ha dicho nada sobre el tema, por lo tanto no se sabe para qué sirve" (France Inter, 2020), y eso desde el punto de vista de los primeros afectados, los italianos, era verdad. Jean-Luc Mélanchon, jefe de un partido de extrema izquierda, reclama desde hace años que Francia no cumpla con los tratados europeos - "Cambiamos la UE o la abandonamos" (Mélanchon, 2016) - , dice hoy lo mismo que Marine Le Pen: "La Unión Europea no hace nada, no sirve de nada, dejémosla por lo tanto dormir en su rincón" (Franceinfo, 2020b). Pero su partido sólo obtuvo el 6\% de los votos en las últimas elecciones europeas.

A nivel europeo, los buenos resultados de partidos poco afines a la $\mathrm{UE}^{3}$, así como el Brexit, lleva hoy a incluir dentro de los escenarios posibles el de una implosión de la UE. Forma parte de los riesgos apuntado por Jacques Delors, de 94 años, expresidente de la Comisión Europea, quien se alarmó a finales de marzo de que "el clima que parece imperar entre los jefes de Estado y de Gobierno, y la falta de solidaridad europea, es un riesgo mortal para la UE" (De Ravinel, 2020).

Sabemos que el primer ministro holandés, hostil a cualquier cambio hacia una organización federalista de la UE, votó en contra de la emisión de una deuda europea a fin de reducir la tasa de interés de los préstamos que tendrán que pedir Italia, Francia o España por motivo de la pandemia. Varios países del norte de Europa piden que toda ayuda común vaya acompañada de una vigilancia de sus políticas económicas. Los tratados impiden igualmente el uso de fondos públicos para salvar empresas. Aunque las instituciones europeas hayan dado respuestas económicas y financieras importantes (préstamos, fondos de garantía, regulación de las diferencias nacionales entre tipos de interés, financiamiento de gastos sanitarios), los estereotipos entre pueblos son fisuras que pueden ser transformadas en grietas por políticos o gobiernos en busca de apoyo popular. A no ser que estas grietas en formación consoliden un movimiento democrático de defensa de la Unión Europea queriendo salvaguardar esta herramienta para crear un sistema de seguridad sanitaria colectiva, luchar contra el cambio climático, desarrollar una potencia científica a la altura de los desafíos contemporáneos y por venir.

3 En 2014, las fuerzas anti UE repartidas en los grupos de Conservadores y Reformistas Europeos (CRE), grupo Europa y la Libertad y de la Democracia Directa y no inscritos han logrado 170 diputados, cerca del $23 \%$ de los escaños, en lugar del 16\% en 2009 (Ivaldi, 2014). 


\section{Conclusión: ¿qué escenarios geopolíticos a corto y medio plazo?}

Imaginar el futuro supone dibujar escenarios, positivos y negativos según los puntos de vista, a largo o mediano plazo. El cielo del "día después" como decimos en Francia, o de la "nueva normalidad" como dicen en España, parece cargado de nubes muy negras, pero lo propio de los escenarios geopolíticos es que sean inciertos.

China transmite la imagen de dominar la difusión del virus en su territorio. En cambio, es posible que los Estados democráticos tengan que gestionar más repuntes de la enfermedad porque carecen de una real capacidad de vigilancia. Salida de la pandemia antes que los demás, China puede además relanzar su tejido industrial gracias a su mercado interno, aunque dependa también de sus importaciones de materias primas. Si Donald Trump es reelegido en 2022, China aprovechará el rechazo del multilateralismo por parte del presidente americano para extender su propia influencia. Con Xi Jinping, China supo tomar el control de puestos muy relevantes en los diferentes organismos de la ONU. Es ahora el tercer contribuyente de la organización y puede influir en la elaboración de normas internacionales. Mientras tanto, los Estados Unidos dejan la UNESCO, suspenden el pago de su cuota en la OMS, amenazan con abandonar el Alto Consejo de lo Derechos del Hombre (HCDH). Los chinos aumentan cuota y número de soldados en operaciones humanitarias cuando Donald Trump quiere disminuir la contribución de su país a tales fines (reducción anunciada de 1.000 millones sobre 6.800 millones de dólares). Xi Jinping quiere más comercio internacional y más cooperación sobre el cambio climático, la energía nuclear, el terrorismo o la salud global, siempre y cuando nadie interfiera en sus asuntos internos. La construcción de infraestructuras e industrias en el mundo entero ("nuevas rutas de la seda") es una poderosa herramienta de soft power y de dominio mediante préstamos. El desarrollo por Huawei de las redes 5G (próxima generación de infraestructura de comunicación) lo será también en Europa, que no tiene empresas de este calibre para desarrollar tales redes aunque podría desarrollarlas a partir de la empresa sueca Ericsson y la finlandesa Nokia. Pero los gobiernos de la UE están de nuevo divididos acerca de la evaluación de la amenaza para la independencia europea que constituye el despliegue de Huawei, y tampoco tienen los mismos intereses que defender en el mercado chino. Alemania es, por ejemplo, uno de los países europeos que más intereses comerciales tiene en China.

Es posible imaginar otro escenario. Sería imprudente creer que los Estados Unidos están en fase de inexorable decadencia, ya que todavía son, con diferencia, la primera potencia económica mundial y tienen el primer rango para la investigación médica. Poseen la eficiencia del triángulo de la investigación compuesto por las universidades, los laboratorios privados y las agencias públicas, entre ellos el muy potente National Institute of Health.

También la dominación del dólar en los intercambios internaciones es incontestable y fortalecida por la extraterritorialidad del derecho estadounidense (aplicación de leyes votadas por las instituciones americanas a personas físicas o morales de países terceros). La reactividad de la economía americana es excepcional, para mal y para bien. Para mal, cuando en tres semanas dieciséis millones de personas se quedaron sin trabajo. Para bien, cuando la recuperación es tan rápida como después de la crisis financiera de 2007. Puede que Donald Trump pierda las elecciones. 
Aunque su sucesor no reanude totalmente el multilateralismo, será más respetuoso de los acuerdos y tratados internacionales y volverá a competir con China para ocupar puestos de poder internacionales necesarios en el ejercicio de su leadership.

En uno u otro de estos escenarios, la Unión Europea sale mal parada. En primer lugar, porque las instituciones supranacionales no estaban preparadas ni tenían el poder para reaccionar en el plano sanitario, y en el plano económico les cuesta mucho obtener unidad para ello. En segundo lugar, por la grietas geopolíticas internas muy profundas en no pocos países (extrema derecha, autoritarismo, secesionismos en el Oeste de Europa; irredentismo húngaro en el Este de Europa) que pueden paralizar su clase política y eclipsar los retos supranacionales. A pesar de la grave crisis económica que se avecina, nuestras sociedades democráticas europeas pueden también impulsar colectivamente un giro ecológico y económicamente virtuoso cuyos efectos se percibirán a largo plazo. Es lo propio de las democracias; sus giros políticos son inciertos, para bien o para mal.

\section{Referencias}

AFP. Agence France Presse. (2020). Coronavirus: un Chinois de 80 ans décède en France, premier mort hors d'Asie. L'obs, 15 de febrero. Recuperado de https://www.nouvelobs.com/topnews/20200215.AFP3258/coronavirus-un-chinois-de80-ans-decede-en-france-premier-mort-hors-d-asie.html

De Ravinel, S. (2020). Le manque de solidarité est un "danger mortel" pour l'Europe, selon Jacques Delors. Le Figaro, 28 de marzo. Recuperado de https://www.lefigaro.fr/politique/le-manque-de-solidarite-est-un-danger-mortel-pour-leurope-selon-jacques-delors-20200328

France Inter. (2020a). Declaration de Marine Le Pen. France Inter, 26 de febrero. Recuperado de https://www.franceinter.fr/emissions/1-invite-de-8h20-le-grand-entretien/linvite-de-8h20-le-grand-entretien-26-fevrier-2020

Franceinfo. (2020). Covid-19: "Pour l'instant, le virus ne circule pas en France", selon un infectiologue (Video). Radio France, 26 de febrero. Recuperado de https://www.francetvinfo.fr/sante/maladie/coronavirus/video-covid-19-pour-1-instant-levirus-ne-circule-pas-en-france-selon-un-infectiologue_3841765.html

Franceinfo. (2020b). Coronavirus : "On voit bien que l'Union européenne est une coalition d'égoïsme", affirme Jean-Luc Mélenchon. Radio France, 1 de abril. Recuperado de https://www.francetvinfo.fr/sante/maladie/coronavirus/coronavirus-on-voit-bien-que-1union-europeenne-est-une-coalition-d-egoisme-affirme-jean-lucmelenchon 3894297.html

Goar, M. (2020). Coronavirus : la défiance et la colère envers la gestion du gouvernement s'installent. Le Monde, 21 de abril. Recuperado de https://www.lemonde.fr/politique/article/2020/04/21/coronavirus-la-defiance-et-lacolere-envers-la-gestion-du-gouvernement-s-installent_6037262_823448.html

Ivaldi, G. (2014). Euroscepticisme, populisme, droites radicales: état des forces et enjeux européens. L'Europe en Formation, (373), 7-28. Recuperado de https://www.cairn.info/revue-1-europe-en-formation-2014-3-page-7.htm

Mélanchon, J.-L. (2016). Conferencia de prensa, después del voto del Brexit. YouTube, 24 de junio. Recuperado de https://www.youtube.com/watch?v=VYqu0NwmAF0 
Méréo, F. (2020). Coronavirus: comment la France se prépare au scénario du pire. Le Parisien, 17 de febrero. Recuperado de http://www.leparisien.fr/societe/sante/coronaviruscomment-la-france-se-prepare-au-scenario-du-pire-17-02-2020-8261067.php 